\title{
Immediate post placental insertion of intrauterine contraceptive device at caesarean delivery: a prospective study
}

\author{
Sravani Mukka*, Madhavi Y.
}

Department of Obstetrics and Gynecology, ESIC Medical College, Hyderabad, Telangana, India

Received: 29 April 2020

Accepted: 06 May 2020

\section{*Correspondence:}

Dr. Sravani Mukka,

E-mail: mukka.sravani@yahoo.com

Copyright: () the author(s), publisher and licensee Medip Academy. This is an open-access article distributed under the terms of the Creative Commons Attribution Non-Commercial License, which permits unrestricted non-commercial use, distribution, and reproduction in any medium, provided the original work is properly cited.

\section{ABSTRACT}

Background: In India almost $65 \%$ of the women have an unmet need for family planning in the first postpartum year. Increasing rates of institutional deliveries creates an opportunity for providing quality post-partum family planning services. Post-partum Intrauterine contraceptive device (PPIUCD), a form of long acting reversible contraception (LARC) is one of the most affective and safest method available. The present study aims at evaluating the safety, efficacy, rate of acceptance and rate of discontinuation of Intra caesarean inserted contraceptive device Copper T380A.

Methods: This was a prospective study conducted at ESIC Medical College, Sanathnagar in women delivered by caesarean section during the period between March 2018 to February 2019. Recruitment was done based on the WHO medical eligibility criteria (MEC) for PPIUCD and also their willingness to participate in the study. Follow-up visits were scheduled at 6 weeks, 3 months and 6 months.

Results: Of the 265 women fulfilling the WHO MEC, $180(67.92 \%)$ were willing to participate in the study. Total acceptance rate was $67.7 \%$. Majority of them belonged to the age group 21-30 years (80\%) and para $2(53.88) .93 .3 \%$ of the women were literates. $12(6.66 \%)$ cases lost to follow up and the complications were studied in the rest 168 women. During follow up $-38.69 \%$ had missing strings, $12.5 \%$ menstrual disturbances, $4.76 \%$ abdominal pain and spontaneous expulsion in $4.1 \%$. No cases of perforation and pregnancy were reported. Total continuation rate was $84 \%$.

Conclusions: PPIUCD is a safe and convenient option of contraception with low expulsion rates and high continuation rates.

Keywords: Copper T-380A, Intra-caesarean, Long acting reversible contraception, Post-partum Intrauterine contraceptive device

\section{INTRODUCTION}

India represents almost $17.85 \%$ of the world's population. ${ }^{1}$ A total $65 \%$ of the women have an unmet need for family planning services in the first postpartum year and the result being $86 \%$ of unintended pregnancies and $85 \%$ of induced abortions. ${ }^{2,3}$ A total $61 \%$ of the births occur at an interval shorter than the recommended birth birth interval of 36 months. According to demographic and health survey, birth-pregnancy interval less than 24 months had 1.1-2.3 times higher risk of babies dying within first year and also more likely to be stunted and underweight than those born 36-47 months apart. ${ }^{4}$

Postpartum amenorrhoea due to breast feeding and postpartum abstinence do delay the next conception but by themselves are not enough to ensure a birth interval of 24 months. Intrauterine contraceptive device, a form of long acting reversible contraception (LARC) is one of the most affective and safest method available with rapid onset of action after administration and rapid return to fertility after discontinuation. Insertion of intra uterine 
contraceptive device can be done in the immediate postpartum period (post placental up to 48 hours after delivery), early postpartum (up to 7 days) and extended postpartum (6 weeks to one year). Its usage is patient independent and has no effect on breast feeding. Cochrane reviews provide evidence of the safety and feasibility of LARC insertion in various settings. ${ }^{5,6}$

India is the first country in the world to adopt an official population policy and launch official family planning program way back in 1952. Despite the constant efforts by the Government of India, unmet needs of contraception still remain high. Returning to Family Planning services after delivery can present multiple challenges to the mother who have competing demands. Thus, immediate post-partum family planning services need to be emphasized wherein women leaves the hospital with effective contraception in place. Delivery is the best opportunity for the insertion of IUCD in developing countries wherein the healthy women comes in contact with the health care provider and may provide a scope to curtail the fertility rate. The number of caesarean deliveries and its complications are in rising trends in the past and present decade. Intra uterine device insertion at the time of caesarean section creates an opportunity to increase access to LARC methods. Government of India has introduced Copper 380A as intra uterine device in 2002 and is approved for 10 years. Although the immediate placement has been associated with high expulsion rates the benefits of immediate insertion in selected population may outweigh the risk of expulsion. There are many reasons for not using contraception specifically LARC like lack of awareness, non-availability of accessible family planning services, social pressure and misconceptions about contraception.

\section{METHODS}

This was a prospective study conducted at ESIC Medical College, Sanathnagar in women delivered by caesarean Section during the period between March 2018 to February 2019. Antenatal counselling was done to all the women attending the out-patient department and also on admission in to the labour room. They were explained regarding the benefits and side effects of $\mathrm{Cu}-\mathrm{T} 380 \mathrm{~A}$. The final recruitment was done based on the WHO medical eligibility criteria (MEC) for IUCD and also their willingness to participate in the study.

\section{Inclusion criteria}

- Women delivered by caesarean section

- Women meeting WHO medical eligibility criteria for PPIUCD

- Women willing to participate in the study.

\section{Exclusion criteria}

- $\quad$ Prolonged rupture of membranes $\geq 18$ hours

- Signs and symptoms of chorioamnionitis
- Unresolved post-partum hemorrhage

- Uterine anomalies/fibroid distorting the uterine cavity

- Anaemia $(\mathrm{Hb}<8 \mathrm{~g} / \mathrm{dl})$

- Pelvic inflammatory disease.

Of the 265 women fulfilling the WHO MEC, 180 $(67.92 \%)$ were willing to participate in the study. 12 $(6.6 \%)$ were lost to follow up and the study was continued in the rest 168 women (Figure 1).

After taking informed consent the required information was collected in the form of questionnaire in a proforma.

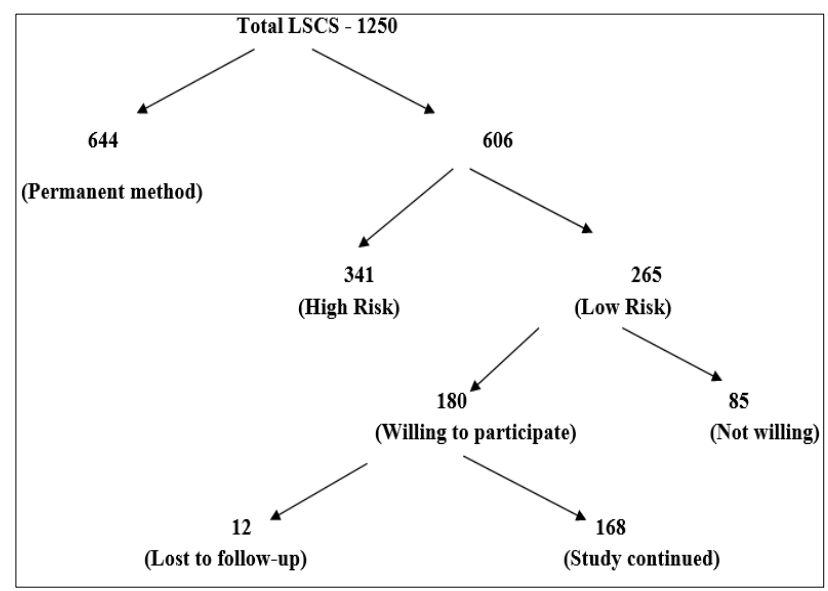

Figure 1: Schematic representation of patient selection.

Intra uterine contraceptive device (IUCD) was placed after the delivery of the placenta in caesarean section. Insertion is done manually by holding the IUCD between index and middle finger of the hand and passing it through the uterine incision. Once it is placed at the level of the fundus fingers are withdrawn slowly noting whether the IUCD remains placed properly. Strings should not be pushed through the cervical canal to prevent its displacement from the fundus and also to avoid uterine infection by contamination with vaginal flora.

Care was taken during closure of uterine incision not to involve the strings in the suture line. Copper $\mathrm{T}$ measuring card mentioning the details of the patient and date of insertion on the back side will be handed over to them.

Follow-up visits were scheduled at 6 weeks, 3 months and 6 months or if she had experienced PAINS (period related problems/pregnancy, abdominal pain, foul smelling vaginal discharge different from the usual lochia suggestive of infection, string related problems).

\section{RESULTS}

Total participants in the present study was 180 with the total acceptance rate being $67.92 \%$. 
Table 1: Reasons for refusal.

\begin{tabular}{|lll|}
\hline Reason & Total $(\mathbf{n}=\mathbf{8 5})$ & $\%$ \\
\hline Misconceptions & 18 & $21.1 \%$ \\
\hline Family refusal & 36 & $42.35 \%$ \\
\hline $\begin{array}{l}\text { No usage of contraception } \\
\text { earlier }\end{array}$ & 10 & $11.76 \%$ \\
\hline Wants other method & 21 & $24.70 \%$ \\
\hline
\end{tabular}

Non acceptance in the present study was due to family pressure in $42.35 \%$ in spite of the repeated counselling. A total $21.1 \%$ had misconceptions like it might cause heavy bleeding, pain and perforation. A total $11.76 \%$ does not want to use any contraception as also not used in the previous pregnancy (Table 1).

Table 2: Age wise distribution.

\begin{tabular}{|lll|}
\hline Age (in years) & Total $(\mathbf{n = 1 8 0})$ & $\%$ \\
\hline$<20$ & 11 & $6.11 \%$ \\
\hline $21-30$ & 144 & $80 \%$ \\
\hline$>30$ & 25 & $13.88 \%$ \\
\hline
\end{tabular}

Table 3: Education.

\begin{tabular}{|lll|}
\hline Education qualification & Total $(\mathbf{n = 1 8 0})$ & $\%$ \\
\hline Illiterate & 12 & $6.66 \%$ \\
\hline Primary & 52 & $28.88 \%$ \\
\hline Secondary & 86 & $47.77 \%$ \\
\hline Graduate and above & 30 & $16.66 \%$ \\
\hline
\end{tabular}

Table 4: Parity.

\begin{tabular}{|lll|}
\hline Parity & Total $(\mathbf{n = 1 8 0})$ & $\%$ \\
\hline P1 & 77 & $42.77 \%$ \\
\hline P2 & 97 & $53.88 \%$ \\
\hline P3 & 06 & $3.33 \%$ \\
\hline
\end{tabular}

Table 5: Complications.

\begin{tabular}{|lll|}
\hline Complications & Total $(\mathbf{n = 1 6 8 )}$ & $\%$ \\
\hline Abdominal pain & 8 & $4.7 \%$ \\
\hline Menstrual disturbances & 21 & $12.5 \%$ \\
\hline Abnormal vaginal discharge & 0 & $0 \%$ \\
\hline Perforation & 0 & $0 \%$ \\
\hline Pregnancy & 0 & $0 \%$ \\
\hline Spontaneous expulsion & 7 & $4.1 \%$ \\
\hline Undescended Strings & 65 & $38.69 \%$ \\
\hline
\end{tabular}

\section{Demographic details of the participants}

Majority of the women were between the age group 2130 years $(80 \%)$ (Table 2) and are more receptive to the counselling. In the present study $93.3 \%$ of the women were literates. $47.77 \%$ had attained secondary education and $16.6 \%$ did their graduation and post-graduation (Table 3). Most of the patients were para $2(53.88 \%)$ followed by para $1(42.77 \%)$ and para $3(3.33 \%)$ (Table 4).

Table 5 shows complications in 168 women as 12 cases were lost to follow-up $-38.69 \%$ had missing strings. $12.5 \%$ had menstrual disturbances at 3 months, expulsion was seen in $7(4.1 \%)$ cases, of which $5(2.8 \%)$ cases were reported at around 6 weeks and 2 cases between 6 weeks and 3 months. Complete expulsion was reported in one case and in the rest 6 cases partial expulsion with IUCD in the cervical canal and vagina was observed. No cases of perforation and pregnancy were reported.

Table 6: Reasons for discontinuation.

\begin{tabular}{|lll|}
\hline Reason & Total $(\mathbf{n}=27)$ & $\%$ \\
\hline Abdominal pain & 2 & $7.40 \%$ \\
\hline Menstrual disturbances & 10 & $37.03 \%$ \\
\hline Family pressure & 08 & $29.62 \%$ \\
\hline Wants permanent methods & 07 & $25.92 \%$ \\
\hline
\end{tabular}

Table 6 shows that the major reason for discontinuation was menstrual disturbances in $37.03 \%$ followed by family pressure in $29.62 \%$. The total continuation rate was $84 \%$.

\section{DISCUSSION}

The increased institutional deliveries give the health care providers an opportunity to effectively counsel and motivate for PPIUCD insertion. Advantages of immediate post-partum insertion are high motivation, assurance that she is not pregnant and convenience. By 2013, 19 states in India have started implementing PPIUCD insertion under National post-partum family planning programme.

In the present study 265 women were selected as per WHO MEC. Of which 180 were willing to participate in the study. The acceptance rate was $67.92 \%$. The acceptance rate of intra-caesarean PPIUCD in a study by Deepti Gupta et al, was $44 \%$ and Kanhere et al, was $36 \% .^{7,8}$ Reason for non-acceptance in the present study was partner or family refusal or either of them not involved in the counselling in $42.3 \%$. Many studies have shown that when partner is involved in contraception counselling and decision making the acceptance and continuation rates were higher. ${ }^{9}$

Majority were in the age group between 21-30 years (80\%) with the mean age 25.5 years. This group was more receptive to the contraceptive counselling, similar to the study by Gupta D et al, where in $76 \%$ were between the age group 21-30 years. 93\% cases of the present study were literates and majority (47.77\%) of them had their secondary education. In a study by Katheit et al, $65 \%$ of the PPIUCD acceptors were educated patients. ${ }^{10}$ Education plays an important role in fertility control. In this study $57.23 \%$ were multipara and 42.77 
were primipara. This is comparable to the study by Grimes et al, where they found higher acceptance in multipara $(65 \%) .{ }^{11}$ In a study by Katheit $34.7 \%$ of the PPIUCD acceptors were P2 and $54 \%$ in Gupta D et al, study.

A total $93.4 \%$ had regular follow-up for 6 months and the rest $6.6 \%$ were lost to follow-up with the probable reasons being distance and lack of support from the family. In Katheit et al, and Gupta D et al, studies $16.6 \%$ and $18.2 \%$ respectively were lost to follow up. Spontaneous expulsion was seen in 7 (4.1\%) cases. Complete expulsion was seen in 1 case and in other 6 cases IUCD was displaced in to the cervical canal or vagina. IUCD was removed and reinserted. This was similar to a multi country study done in Belgium, Chile and Philippines which showed rates of expulsion at one month ranging from 4.6-16\%. ${ }^{12}$ Expulsion rates were $10.5 \%$ in Katheit et al, study and $2 \%$ in a study by Gupta A et al. ${ }^{13}$ Expulsion rates can be reduced by using proper technique during insertion. Techniques can be improved by conducting frequent training programmed to health care professionals. A WHO multicenter trial has shown PPIUCD expulsion rates at 6 months ranged from 31\%$41 \% .^{14}$

Missing or undescended threads were seen in $38.69 \%$ and the major reasons being curling and retraction of the threads in to the cervical canal and uterine cavity. Pelvic Ultrasound was done to confirm the position of Copper T. In a study by Patel $\mathrm{J}$ et al, missing threads in intra caesarean PPIUCD was $27 \%{ }^{15}$ The rate is higher upto $65 \%$ in a study by Hooda R et al. ${ }^{16} 4.7 \%$ of the patients complained of pain abdomen relieved with analgesics. This coincides with the studies by Halder A et al, and Patel J where $4 \%$ and $4.5 \%$ of the intra caesarean PPIUCD group reported pain abdomen. ${ }^{17}$

Menstrual disturbances were seen in $12.5 \%$ comparable to a study by Gupta D with $9.1 \%$ having abnormal uterine bleeding. There were no cases of pregnancy, perforation and pelvic inflammatory disease. A total $84 \%$ were comfortable with PPIUCD and continued using it. Major reason for discontinuation was menstrual disturbances in $37.03 \%$ followed by family pressure in $29.62 \%$. Removal was done with artery forceps. 3 cases required paracervical block and for one case dilatation and curettage was done in Operation Theatre as it was embedded. Final acceptance and continuation depend on literacy, parity, partners involvement in counselling and social factors.

\section{CONCLUSION}

PPIUCD is a safe and convenient option of contraception with low expulsion rates and high continuation rates. Missing threads were a major problem that can be reduced by proper training. Training programmes on PPIUCD to increase knowledge and skills among health care providers should be conducted.
Healthy timing and spacing of pregnancy have a positive effect on maternal health and new born outcomes. A baby should be born because it is wanted, not because it cannot be prevented.

\section{Funding: No funding sources \\ Conflict of interest: None declared}

Ethical approval: The study was approved by the Institutional Ethics Committee

\section{REFERENCES}

1. Population of India. 2017. Available at: https://www.indiaonline pages.com/population/indiacurrent-population.html. Accessed on $21^{\text {st }}$ February 2020.

2. Post-partum IUCD reference manual, family planning division. Ministry of Health and Family Welfare, Go vernment of India, New Delhi, India; 2010. Available at: http://www.nrhmtn.gov.in/ modules/PPIUCD\%20Reference\%20Manual.pdf. Accessed on $21^{\text {st }}$ February 2020.

3. Huang YM, Merkatz R, Kang JZ, Roberts K, Hu $\mathrm{XY}$, Di Donato $\mathrm{F}$, et al. Postpartum unintended pregnancy and contraception practice among ruralto-urban migrant women in Shanghai. Contracept. 2012;86(6):731-8.

4. Rutstein SO, Macro OR. Fertility levels, trends, and differentials 1995-1999. Available at: https://agris.fao.org/agris-search/search.do?recordID =XF2015035876. Accessed on $21^{\text {st }}$ February 2020.

5. Grimes DA, Lopez LM, Schulz KF, Van Vliet HA, Stanwood NL. Immediate post-partum insertion of intrauterine devices. Cochrane Data Syst Rev. 2010(5):CD003036.

6. Grimes K, Schluz H, Van Vliet, N. Stanwood. Immediate Post-Partum insertion of intra uterine devices. Cochrane Data Syst Rev. 2003;CD00306.

7. Gupta D, Sharma S, Kanhere A, Jahan I. Study of acceptance of intra-cesarean IUCD as method of contraception. Int J Reprod Contracept Obstet Gynecol. 2017;6(11):5033-7.

8. Kanhere AV, Pateriya P, Jain M. Acceptability and feasibility of immediate post-partum IUCD insertion in a tertiary care in Central India. Int $\mathrm{J}$ Reprod Contracept Obstet Gynecol. 2015;4(1):179-84.

9. Celen S, Moroy P, Sucak A. Clinical outcomes of early post placental insertion of intrauterine contraceptive devices. Contracept. 2004;69:279-82.

10. Katheit G, Agarwal J. Evaluation of post placental intra uterine device (PPIUCD) in terms of awareness, acceptance and expulsion in a tertiary care centre. Int J Reprod Contracept Obstet Gynecol. 2013;2:539-43.

11. Grimes D, Schluz K, Van Vliet H. Immediate postpartum insertion of intra uterine devices:a Cochrane review. Human Reprod. 2001;17(3):549-54.

12. Blanchard H, Mac Kiag C, ACCESS-FP Program. Post-partum contraception. 2006. Available at: http://www.k4health.org/sites/default/files/postpartu 
mabortion_English.pdf. Accessed on $21^{\text {st }}$ February 2020.

13. Gupta A, Verma A, Chauhan J. Evaluation of PPIUCD versus interval IUCD (380A) insertion in a teaching hospital of Western U.P. Int $\mathbf{J}$ Reprod Contracept Obstet Gynecol. 2013;2(2):204-8.

14. Singals, Bharati R, Dewan R. Clinical outcome of post placental copper 380A insertion in women delivering by caesarean section. J Clin Diagn Res. 2014;8(9):OC04.

15. Patel J, Vyas R, Shah S, Parikh P. Evaluation of PPIUCD insertion as a method of contraception in India. IOSR-JDMS. 2017;16(6):49-53.

16. Hooda R, Mann S, Nanda S, Gupta A, More H, Bhutani J. Immediate postpartum intrauterine contraceptive device insertions in caesarean and vaginal deliveries: a comparative study of follow-up outcomes. Int J Reproduct Medi. 2016;2016.

17. Halder A, Sowmya MS, Gayen A, Bhattacharya P, Mukherjee S, Datta $S$, et al. A retrospective study to evaluate vaginal insertion and intra caesarean insertion of post-partum intra uterine contraceptive device. J Obstet Gynecol India. 2016;66(1):35-41.

Cite this article as: Mukka S, Madhavi Y. Immediate post placental insertion of intrauterine contraceptive device at caesarean delivery: a prospective study. Int J Reprod Contracept Obstet Gynecol 2020;9:2244-8. 